\title{
Green revolution and Farmers welfare!!
}

\section{Editorial}

May be a lot of people think that agriculture after the green revolution benefited many farmers. But the reality is not. After the industrial revolution the world's agriculture progressed, but this progress does not benefit all farmers equally. The success of the Green Revolution after chemical industry was dependent on those inputs and crop varieties that are not available to all farmers in the world or are so expensive.

On the one hand, the success of intensive farming systems to run is depend on large lands so as to reduce costs and increase production. So, mechanization should also be developed. But here is an important question. Will the move to these systems affect the social structure of rural communities and farmers?

The fact is that many smallholder farmers cannot afford the cost of such systems, and are not large landowners. This is caused due to the lack of competitiveness of smallholder farmers compared to large farmers to occupy world market; many farmers around the world not take advantage of Green Revolution.

The study on the agriculture status in underdeveloped and even some developing countries show that after the Green Revolution, many farmers tend to have other jobs, because their agriculture to no avail. The high cost of inputs and labor, led to instability of cost-effectiveness of these systems. This leads to a rupture of the social structure of many rural families, along with important social consequences such as unemployment and jobs tend to be false. In this regard, a lot of people who were active in the production cycle, joined to the cycle of consumption and it has led to rising unemployment.

Such changes in the social structure of rural communities could have different causes which are contrary to the principles of sustainable development. One of the most important principles of sustainable agricultural systems is the family savings or net worth is consistently going up. Capitalism in agriculture after green revolution was one of the events which was not beneficial for smallholder farmers at all. The consequences of "concentration" in the agriculture section could be a new horizon in studies to clarify the realities of intensive agriculture movement.

After the Green Revolution, which was more a result of the Industrial Revolution and biotechnology, farmers tend to high-yield varieties much increased. Since biotechnology focused on certain plants, such as wheat, rice and corn, farmers want to grow these plants increased. This tendency led to a new movement so called "specification". This tendency enveloped the world as a fever, because of the economic aspect was attractive to farmers. Meanwhile, these plants were supported and subsidized by governments. But we clean forgot that "diversity" is one of the most important factors which stabilize the systems.

Monoculture crops had led to native plants in many areas become neglected and the new plants consequences adversely affected the ecology of habitats. For example, in many systems, weeds became dominant in crops and their seed bank was guaranteed to remain for decades to come.

\author{
Volume 2 Issue 4 - 2015
}

\section{Behnam Kamkar}

Department of Agronomy, Gorgan University of Agricultural Sciences and Natural Resources (GUASNR), Iran

Correspondence: Behnam Kamkar, Associate Professor, Department of Agronomy, Gorgan University of Agricultural Sciences and Natural Resources (GUASNR), Iran, P.O.Box 4918946464, Tel +98-91 I 2734I53, 98- I7I-4427060, Email kamkar@gau.ac.ir

Received: July 20, 2015 | Published: August 14, 2015

Undoubtedly, Green Revolution had an important and effective role in world food security, but it seems it is necessary to study other aspects of the impact of this revolution on human society. The fact is that these systems have a significant role in the world food supply, but most of their roles in enhancing the welfare of farmers are limited to developed countries and to a much less in developing and underdeveloped countries. Undoubtedly, these systems will benefit other farmers if their industry could supply their needs in machinery and inputs with focusing on indigenous-knowledge- based technologies. On the other hand, these industries should engage a part of the labors (from rural communities) in the industrial sector.

To cut a long story short, we could see that a lot of smallholder farmers are poorer than ever in underdeveloped and developing countries and this is the alarm to disintegrate agricultural and rural social structure in many of these countries. The decline in production in these countries and on the one hand injustice in the distribution of food in the world has caused food today as a tool of political pressure on these countries to become. Is this in line with moving to a sustainable world?

The purpose of this note is saying that just looking at the economic content of the green revolution led to that we're unaware of other aspects of the impact of this revolution, although environmental aspects are more pronounced. Although Green Revolution increased world income of agriculture sector, but has not led to the welfare of all farmers

In this regard, restore the rural community's structures, returning the farmers into agricultural lands and re-insert them into production cycle are the first priorities. This goal is achievable except that in addition to the economic aspects in general, the welfare of farmers and the rural communities improve.

Now this question arise: what is the role of researchers in this field? Researchers need to challenge and criticize Green Revolution. Of course, we are looking forward fair criticism. Unfortunately, one of the reasons that in recent decades the concept of sustainability could not well be developed in practice was irrational criticisms or exaggeration in definitions. Let us not forget that sustainable agriculture is not a utopia. We must present realistic definitions. When the definitions are true, these definitions make it easier for farmers to accept and move towards the implementation of this system will be simplified. 
Sustainable agriculture is a new horizon which is the human hope to provide food security and safety simultaneously, along with environmental conservation. But, the first step in achieving it just depends on true terminology. This concept should be considered as a multidimensional concept which all people and especially farmers in all countries must benefit from it and this is the missing link in the current agricultural exists.

\section{Acknowledgements}

None.

\section{Conflict of interest}

The author declares no conflict of interest. 